\title{
Health Care Burden of Dyspepsia Among Nonvalvular Atrial Fibrillation Patients
}

\author{
Michael H. Kim, MD; Kelly F. Bell, PharmD, MSPhr; Dinara Makenbaeva, MD; \\ Daniel Wiederkehr, BS; Jay Lin, PhD, MBA; and John Graham, PharmD
}

\begin{abstract}
BACKGROUND: Although dyspepsia is common among nonvalvular atrial fibrillation (NVAF) patients, its impact on patient health and cost has not been adequately studied.

OBJECTIVE: To evaluate the incremental health care burden associated with dyspepsia among NVAF patients and its impact on warfarin treatment.

METHODS: NVAF patients $\geq 18$ years of age with continuous insurance coverage were identified (January 1, 2007, to December 31, 2009) from the MarketScan Commercial and Medicare Research databases. Patients with 1 inpatient or 2 outpatient dyspepsia diagnoses within 12 months following any NVAF diagnosis were grouped into the dyspeptic cohort, and patients without any dyspepsia diagnosis were grouped into the nondyspeptic cohort. Of the overall cohorts, patients were matched by key patient characteristics. Dyspepsia was further categorized as having a prior history of dyspepsia (chronic) or no dyspepsia (nonchronic) during the baseline period. Health care resource utilization, associated costs, and warfarin use were evaluated during a 12-month follow-up period.
\end{abstract}

RESULTS: Of NVAF patients included in the study ( $\mathrm{N}=142,322), 10.4 \%$ were diagnosed with dyspepsia. After matching for key characteristics, NVAF patients with dyspepsia had significantly greater inpatient, outpatient, and prescription claims per patient year than those without dyspepsia $(1.24 \pm 1.21$ vs. $0.36 \pm 0.68, P<0.0001 ; 110.18 \pm 101.03$ vs. $66.98 \pm 72.43, P<0.0001$; and $52.13 \pm 35.30$ vs. $44.29 \pm 32.41, P<0.0001$, respectively). This greater number of claims was reflected in higher annual inpatient, outpatient, and prescription payments $(\$ 23,610 \pm \$ 54,748$ vs. $\$ 5,509 \pm \$ 19,142, P<0.0001 ; \$ 18,182 \pm \$ 28,790$ vs. $\$ 9,765 \pm \$ 22,009$, $P<0.0001$; and $\$ 4,661 \pm \$ 5,628$ vs. $\$ 3,897 \pm \$ 4,586, P<0.0001$, respectively). NVAF patients with chronic dyspepsia were the least likely to take warfarin for stroke prevention.

CONCLUSIONS: NVAF patients with dyspepsia experienced more all-cause hospitalizations and required more outpatient medical services, all associated with greater expenditures than NVAF patients without dyspepsia. Additionally, dyspepsia may be a barrier to warfarin use among NVAF patients.

J Manag Care Pharm. 2014;20(4):391-99

Copyright $\odot 2014$, Academy of Managed Care Pharmacy. All rights reserved.

\section{What is already known about this subject}

- Atrial fibrillation (AF) is the most common cardiac arrhythmic disorder in the United States and is estimated to affect approximately $1 \%$ of adult Americans, of which the majority ( $85 \%)$ are 65 years of age and older.
- A recent study by LaMori et al. (2012), in which an Internetbased, self-administered questionnaire was used, reported that $34 \%$ of AF patients responded as having any of the following conditions: ulcers, abdominal bloating, abdominal pain (or discomfort), gastroesophageal reflux disease, or heartburn.

- Additionally, this study reported that in comparison with AF patients who did not have dyspepsia, AF patients with dyspepsia used outpatient health care resources to a greater extent during a 6-month follow-up period and were less likely to be treated with anticoagulation therapy for reducing stroke risk.

\section{What this study adds}

- We conducted an analysis using a large, nationally representative database of medical claims to assess the health care burden of dyspepsia among adult nonvalvular atrial fibrillation (NVAF) patients.

- The results of this study suggest dyspepsia significantly impacts health care resource use and costs, which for all health care claims were 2.4-fold higher among NVAF patients with dyspepsia, as diagnosed by ICD-9-CM codes, relative to NVAF patients without dyspepsia.

- Warfarin use was significantly less frequent among NVAF patients with dyspepsia, independent of stroke risk, suggesting dyspepsia may be a potential barrier to its use.

A trial fibrillation (AF) is the most common cardiac arrhythmic disorder in the United States and is estimated to affect approximately $1 \%$ of adult Americans, of which the majority $(\sim 85 \%)$ are 65 years of age and older. ${ }^{1,2}$ With the growing elderly population in the United States, the prevalence of AF is expected to more than double by 2050. ${ }^{1,2}$ People with AF have up to a 5-fold increased risk of stroke, with stroke risk being highest for persons between the ages of 80 and 89. ${ }^{3}$ Another common condition more frequent in persons older than 65 years of age is dyspepsia, a gastrointestinal (GI) disorder widely defined by symptoms of postprandial fullness, early satiation, and epigastric pain, or discomfort or burning in the absence of causative structural disease. ${ }^{4}$ A review of several U.S. studies reported that the pooled prevalence of dyspeptic, gastroesophageal, and dyspeptic and/or gastroesophageal symptoms was $16.3 \%$ among the general U.S. population. ${ }^{5}$ 
A recent study by LaMori et al. (2012) in which an Internetbased, self-administered questionnaire was used, reported that $34 \%$ of AF patients responded as having any of the following conditions: ulcers, abdominal bloating, abdominal pain, gastroesophageal reflux disease (GERD), or heartburn. ${ }^{6}$ Additionally, this study reported that in comparison to $\mathrm{AF}$ patients who did not have dyspepsia, AF patients with dyspepsia used outpatient health care resources to a greater extent during a 6-month follow-up period and were less likely to be treated with anticoagulation therapy for reducing stroke risk. ${ }^{6}$ A second study conducted in Japan also reported a high prevalence of dyspepsia among AF patients (37\%); however, warfarin use was similar among AF patients with dyspepsia (30\%) and AF patients without dyspepsia (32\%) in this study. ${ }^{7}$ As the majority of AF patients have a moderate to high stroke risk (i.e., $\mathrm{CHADS}_{2} \geq 2$ [stroke risk guidelines for $\mathrm{AF}$ patients]), and as these studies report that only about one-third of AF patients are treated with anticoagulation therapy, it appears that many patients who should be treated with anticoagulation therapy are not. ${ }^{6-8}$

Another recent study conducted by LaMori et al. (2013) reported that only $48 \%$ of patients at high risk of stroke reported use of anticoagulation therapy. ${ }^{9}$ There are multiple barriers to anticoagulation therapy, including GI side effects. Medications for reducing the risk of stroke are associated with different GI side effect profiles, with a systematic review of randomized clinical trials having reported incidences of GI symptoms in $0.2-17.9 \%$ of AF patients taking aspirin, $0.0-14.1 \%$ of AF patients taking vitamin $\mathrm{K}$ antagonists (including warfarin), $23 \%$ of AF patients taking direct thrombin inhibitors, and $2.4 \%$ of AF patients taking a factor Xa inhibitor..$^{10}$ The authors of this review also noted that the occurrence of GI symptoms in AF patients taking some medications used for thromboprophylaxis was associated with higher rates of stroke medication discontinuation. ${ }^{10}$

More thoroughly understanding the health care burden of dyspepsia and other GI disorders among AF patients is important, as that burden may influence the stroke preventative treatment decision-making process. We conducted an analysis of adult nonvalvular atrial fibrillation (NVAF) patients using a large, nationally representative database of medical claims to assess the health care burden of dyspepsia, with dyspepsia more inclusively defined by specific International Classification of Diseases, Ninth Revision, Clinical Modification (ICD-9-CM) codes. ${ }^{11}$ We also examined the association between dyspepsia and the frequency of anticoagulation treatment.

\section{Methods}

\section{Study Population}

Adult patients with 1 inpatient diagnosis or $\geq 2$ distinct outpatient diagnoses for AF (ICD-9-CM code 427.31) were identified from the MarketScan Commercial and Medicare Research databases between January 1, 2007, and December 31, 2009 These databases, encompassing millions of patients, contain inpatient, outpatient, and prescription drug information. The medical claims data facilitate longitudinal studies by providing standardized, patient- and provider-level de-identified data spanning extensive time periods. AF patients were excluded from the study population if they were $<18$ years of age, had cardiac valvular disease as identified by ICD-9-CM codes and Current Procedural Terminology (CPT) codes, or had transient $\mathrm{AF}$, defined by the existence of one of the following criteria ${ }^{12}$ : a diagnosis of hyperthyroidism, use of either methimazole or propylthiouracil during the baseline period (identified by ICD-9-CM and National Drug Codes), or presence of a cardiac surgical procedure within the 30-day period prior to the index event (identified by ICD-9-CM and CPT codes).

From the overall study population, NVAF patients who had 1 inpatient or $\geq 2$ outpatient primary or secondary diagnoses (including emergency room visits) on 2 different dates for dyspepsia, where at least 1 diagnosis occurred within a 12-month period following any diagnosis of NVAF (January 1, 2007, to December 31, 2009), were identified and grouped into the dyspeptic cohort. Dyspepsia diagnoses were defined as abdominal pain, abdominal discomfort, and dyspepsia in accordance with the Randomized Evaluation of Long-Term Anticoagulation Therapy (RE-LY) trial in which they were validated by RE-LY investigators (ICD-9-CM codes 787.1, 789.0, 789.4, 789.6, or 536.8). ${ }^{11}$ The earliest identified dyspepsia diagnosis was defined as the index event. The baseline and follow-up periods consisted of 12 months prior to and following the index date. The study periods are further defined in Figure 1.

NVAF patients with dyspepsia were also categorized as having a prior history of dyspepsia (chronic) or no dyspepsia (nonchronic) during the baseline period. To identify the nondyspeptic cohort, NVAF patients were required to have no diagnoses of dyspepsia during the entire study period. For the nondyspeptic cohort, a random date between the earliest NVAF diagnosis date and the end of patient enrollment or December 31, 2009, or 12 months post-index date, whichever was earlier, was selected as the index date. All patients within the study population were required to have 12 months of continuous health care coverage prior to and following the index date. Since this study did not involve "identifiable human subjects," it was exempt from compliance with Common Rule, 45 CFR $\S 46.101(b)(4)$.

\section{Patient Matching}

Patients within the nondyspeptic cohort were matched 1:1 to patients within the dyspeptic cohort. Patient characteristics included in the matching process were age (within 1 year of each other), and exact match of gender, region, health plan type, and Deyo-Charlson Comorbidity Index (CCI). 


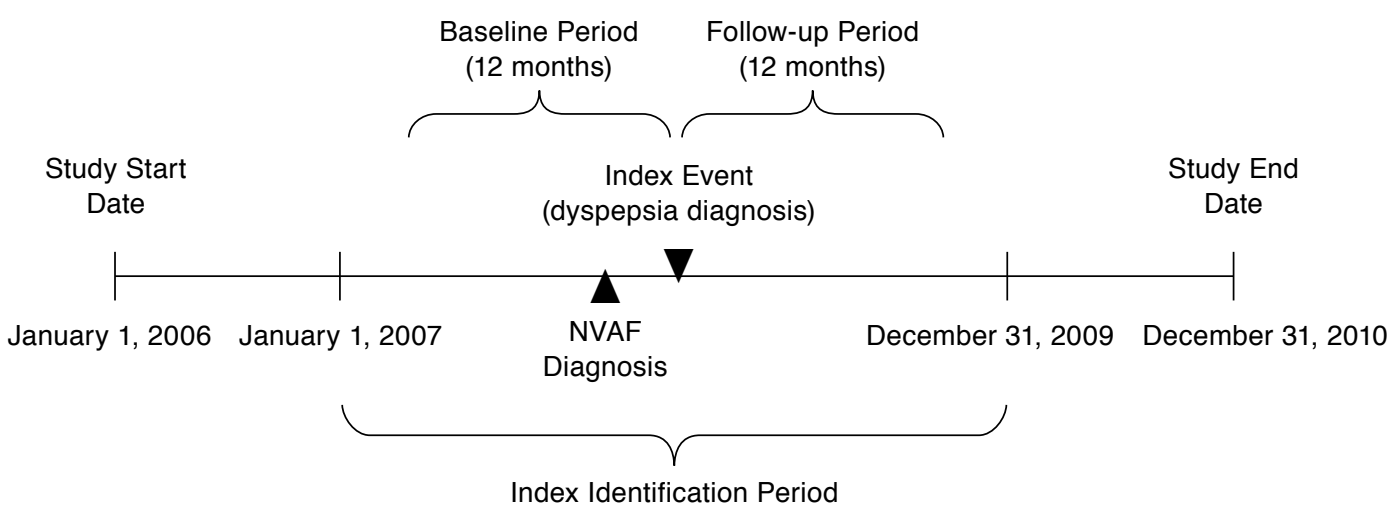

a Not drawn to scale.

\section{Baseline Characteristics}

Demographics and clinical characteristics including baseline dyspepsia and warfarin use, CCI, and $\mathrm{CHADS}_{2}$ scores were evaluated prior to the index event for study cohorts.

\section{Warfarin Use}

To examine the frequency of anticoagulation treatment, warfarin use as stratified by $\mathrm{CHADS}_{2}$ score was assessed during the 12-month baseline and follow-up periods. At the time of data collection for this study, other oral anticoagulants for the treatment of NVAF patients had not been approved by the U.S. Food and Drug Administration, except for dabigatran, which was approved in October 2010. Evaluation of dabigatran in the follow-up period showed that only $0.03 \%$ of the study population used this drug. Based on the low proportion of patients using dabigatran for the treatment of NVAF, it was not evaluated in this analysis.

\section{Health Care Utilization and Payments}

Health care resource utilization and associated payments were determined for the matched dyspeptic and nondyspeptic cohorts. The following resource categories were evaluated: all-cause and dyspepsia-related, GI-related, GI bleed-related inpatient and outpatient claims, and all-cause outpatient prescription claims. Additionally, hospital length of stays (LOS) for all-cause, dyspepsia-related, GI-related, and GI bleed-related inpatient claims were determined.

\section{Sensitivity Analysis}

As a sensitivity analysis, we conducted multivariable regression analyses using generalized linear models (GLM) to evaluate the impact of dyspepsia on health care resource utilization for all causes and their associated costs among unmatched cohorts. Covariates in the GLM models included age, gender, region, health plan type, CCI, and $\mathrm{CHADS}_{2}$ scores. For the GLM regressions, a gamma distribution with log transformation was used to analyze the cost data, and binomial distributions with log transformation were used to analyze the data of hospitalization count, total hospital LOS, outpatient medical services claims count, and outpatient prescription claims count.

\section{Statistical Analyses}

Descriptive statistics were used to describe demographics, clinical characteristics, and unadjusted health care resource utilization and costs of patient cohorts. T-tests and chi-square tests were used to detect statistically significant differences in continuous and categorical variables, respectively. A critical value of 0.05 was used to determine statistical significance. Statistical analyses were carried out using SAS 9.2 (SAS Institute, Cary, NC).

\section{Results}

\section{Study Population}

Of the overall NVAF study population, 127,766 were included in the nondyspeptic cohort, and 14,556 (10.4\%) were included in the dyspeptic cohort. From the overall study population, 14,086 NVAF patients with dyspepsia and 14,086 NVAF patients without dyspepsia were matched by key patient characteristics.

\section{Baseline Characteristics}

Among the unmatched cohorts, mean age of dyspeptic patients was greater than that of nondyspeptic patients $(73.68 \pm 12.40$ vs. $72.09 \pm 12.93$ years, $P<0.0001)$ and a greater proportion of female NVAF patients were grouped in the dyspeptic cohort $(52.05 \%$ vs. $40.94 \%, P<0.0001)$. The mean CCI for the unmatched dyspeptic cohort was significantly greater compared with the nondyspeptic cohort $(2.43 \pm 2.20$ 
Health Care Burden of Dyspepsia Among Nonvalvular Atrial Fibrillation Patients

\section{TABLE 1 Baseline Characteristics of NVAF Cohorts}

\begin{tabular}{|c|c|c|c|c|c|c|c|c|c|c|}
\hline & \multicolumn{4}{|c|}{$\begin{array}{l}\text { Unmatched Cohorts } \\
\qquad(\mathrm{N}=142,322)\end{array}$} & \multirow[b]{3}{*}{$P$ Value } & \multicolumn{4}{|c|}{$\begin{array}{l}\text { Matched Cohorts } \\
\quad(\mathrm{N}=28,172)\end{array}$} & \multirow[b]{3}{*}{$P$ Value } \\
\hline & \multicolumn{2}{|c|}{$\begin{array}{c}\text { Dyspeptic } \\
(\mathrm{n}=14,556)\end{array}$} & \multicolumn{2}{|c|}{$\begin{array}{c}\text { Nondyspeptic } \\
(\mathrm{n}=127,766)\end{array}$} & & \multicolumn{2}{|c|}{$\begin{array}{l}\text { Dyspeptic } \\
(\mathrm{n}=14,086)\end{array}$} & \multicolumn{2}{|c|}{$\begin{array}{c}\text { Nondyspeptic } \\
(n=14,086)\end{array}$} & \\
\hline & $\mathrm{n}$ & $\%$ & $\mathbf{n}$ & $\%$ & & $\mathbf{n}$ & $\%$ & $\mathrm{n}$ & $\%$ & \\
\hline \multicolumn{11}{|l|}{ Age } \\
\hline Mean & \multicolumn{2}{|c|}{73.68} & \multicolumn{2}{|c|}{72.09} & $<0.0001$ & \multicolumn{2}{|c|}{73.95} & \multicolumn{2}{|c|}{73.96} & 0.9881 \\
\hline $\mathrm{SD}$ & \multicolumn{2}{|c|}{12.40} & \multicolumn{2}{|c|}{12.93} & & \multicolumn{2}{|c|}{12.01} & \multicolumn{2}{|c|}{11.99} & \\
\hline Median & \multicolumn{2}{|c|}{76.00} & \multicolumn{2}{|c|}{75.00} & & \multicolumn{2}{|c|}{76.00} & \multicolumn{2}{|c|}{77.00} & \\
\hline Age group (years) & & & & & $<0.0001$ & & & & & 0.9992 \\
\hline $18-35$ & 101 & 0.69 & 1,064 & 0.83 & & 66 & 0.47 & 64 & 0.45 & \\
\hline $36-45$ & 272 & 1.87 & 2,992 & 2.34 & & 232 & 1.65 & 234 & 1.66 & \\
\hline $46-55$ & 938 & 6.44 & 10,407 & 8.15 & & 863 & 6.13 & 848 & 6.02 & \\
\hline $56-65$ & 2,216 & 15.22 & 23,250 & 18.20 & & 2,132 & 15.14 & 2,140 & 15.19 & \\
\hline $66-75$ & 3,301 & 22.68 & 29,591 & 23.16 & & 3,240 & 23.00 & 3,245 & 23.04 & \\
\hline$\geq 76$ & 7,728 & 53.09 & 60,462 & 47.32 & & 7,553 & 53.62 & 7,555 & 53.63 & \\
\hline \multicolumn{11}{|c|}{ Charlson Comorbidity Index (CCI) } \\
\hline Mean & \multicolumn{2}{|c|}{2.43} & & & $<0.0001$ & & & & & 1.0000 \\
\hline SD & & & & & & & & & & \\
\hline Median & & & & & & & & & & \\
\hline CCI Group & & & & & $<0.0001$ & & & & & 1.0000 \\
\hline 0 & 2,746 & 18.87 & 43,543 & 34.08 & & 2,717 & 19.29 & 2,717 & 19.29 & \\
\hline $1-2$ & 5,973 & 41.03 & 53,525 & 41.89 & & 5,908 & 41.94 & 5,908 & 41.94 & \\
\hline $3-4$ & 3,697 & 25.40 & 21,584 & 16.89 & & 3,613 & 25.65 & 3,613 & 25.65 & \\
\hline$\geq 5$ & 2,140 & 14.70 & 9,114 & 7.13 & & 1,848 & 13.12 & 1,848 & 13.12 & \\
\hline Gender & & & & & $<0.0001$ & & & & & 1.0000 \\
\hline Male & 6,979 & 47.95 & 75,463 & 59.06 & & 6,782 & 48.15 & 6,782 & 48.15 & \\
\hline Female & 7,577 & 52.05 & 52,303 & 40.94 & & 7,304 & 51.85 & 7,304 & 51.85 & \\
\hline Region & & & & & $<0.0001$ & & & & & 1.0000 \\
\hline Northeast & 1,626 & 11.17 & 15,586 & 12.20 & & 1,550 & 11.00 & 1,550 & 11.00 & \\
\hline North central & 5,260 & 36.14 & 41,631 & 32.58 & & 5,122 & 36.36 & 5,122 & 36.36 & \\
\hline South & 4,962 & 34.09 & 41,652 & 32.60 & & 4,833 & 34.31 & 4,833 & 34.31 & \\
\hline West & 2,641 & 18.14 & 28,184 & 22.06 & & 2,538 & 18.02 & 2,538 & 18.02 & \\
\hline Unknown & 67 & 0.46 & 713 & 0.56 & & 43 & 0.31 & 43 & 0.31 & \\
\hline Health plan type & & & & & $<0.0001$ & & & & & 1.0000 \\
\hline Missing & 309 & 2.12 & 2,864 & 2.24 & & 232 & 1.65 & 232 & 1.65 & \\
\hline Comprehensive & 4,793 & 32.93 & 42,239 & 33.06 & & 4,714 & 33.47 & 4,714 & 33.47 & \\
\hline EPO & 37 & 0.25 & 346 & 0.27 & & 29 & 0.21 & 29 & 0.21 & \\
\hline $\mathrm{HMO}$ & 1,317 & 9.05 & 14,946 & 11.70 & & 1,236 & 8.77 & 1,236 & 8.77 & \\
\hline POS & 601 & 4.13 & 6,186 & 4.84 & & 548 & 3.89 & 548 & 3.89 & \\
\hline $\mathrm{PPO}$ & 7,386 & 50.74 & 59,742 & 46.76 & & 7,248 & 51.46 & 7,248 & 51.46 & \\
\hline POS with capitation & 20 & 0.14 & 285 & 0.22 & & 15 & 0.11 & 15 & 0.11 & \\
\hline CDHP & 93 & 0.64 & 1,158 & 0.91 & & 64 & 0.45 & 64 & 0.45 & \\
\hline
\end{tabular}

$\mathrm{CDHP}=$ Consumer-driven health plan; $\mathrm{EPO}=$ exclusive provider organization; $\mathrm{HMO}=$ health maintenance organization; $N V A F=$ nonvalvular atrial fibrillation;

$P O S=$ point of service; $P P O=$ preferred provider organization; $S D=$ standard deviation

vs. $1.61 \pm 1.82, P<0.0001$ ). Other demographic characteristics, including age group, region, and health plan type also differed (Table 1). For matched cohorts, patients were similar in baseline characteristics as a result of the matching process.

\section{Other Clinical Characteristics of Matched Cohorts}

Other clinical characteristics not used in the matching process of the dyspeptic and nondyspeptic cohorts are presented in
Table 2. The mean $\mathrm{CHADS}_{2}$ score was significantly greater for the nondyspeptic cohort $(1.85 \pm 1.23$ vs. $1.78 \pm 1.20, P<0.0001)$, but the slightly greater score may not be clinically relevant. In comparison to NVAF patients without dyspepsia, significantly fewer NVAF patients who had dyspepsia took warfarin for stroke prevention during the baseline period $(60.70 \%$ vs $44.98 \%, P<0.0001)$. 


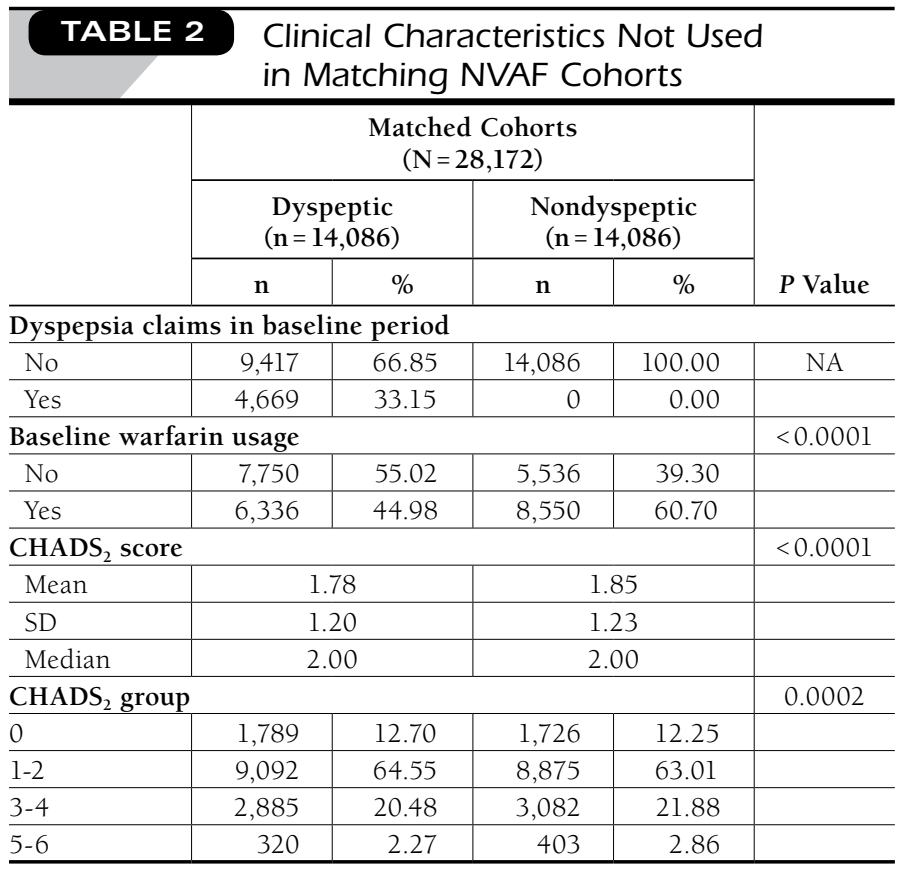

$\mathrm{CHADS}_{2}=$ stroke risk guidelines for AF patients; $\mathrm{NA}=$ not applicable; $\mathrm{NVAF}=$ nonvalvular atrial fibrillation; $S D=$ standard deviation.

\section{Health Care Resource Utilization and Payments}

Health care resource utilization of the matched study population is presented in Table 3. Among the matched study population, dyspepsia was associated with an incremental, dyspepsia-related hospitalization of $0.65 \pm 0.66$ per patient year with a LOS of $4.91 \pm 8.59$ days and cost of $\$ 13,450 \pm \$ 36,808$. Patients in the dyspeptic versus nondyspeptic matched cohort had higher rates of GI-related hospitalizations $(0.83 \pm 0.86$ vs. $0.06 \pm 0.25$ per patient year, $P<0.0001)$ with greater LOS $(6.21 \pm 11.07$ vs. $0.34 \pm 2.47$ days, $P<0.0001)$ and higher costs $(\$ 17,258 \pm \$ 45,742$ vs. $\$ 997 \pm \$ 9,262, P<0.0001)$. The mean number of GI bleeds requiring inpatient care $(0.10 \pm 0.34$ vs. $0.02 \pm 0.14$ per patient year, $P<0.0001)$ and associated LOS $(1.10 \pm 5.27$ vs. $0.14 \pm 1.87$ days, $P<0.0001)$ were also greater for the dyspeptic cohort in comparison with the nondyspeptic cohort. Additionally, the number of dyspepsia-related, GI-related, and GI bleed-related outpatient medical service claims and their associated costs were greater for the dyspeptic versus the nondyspeptic cohort.

Regarding health care utilization for all causes, the mean number of inpatient claims $(1.24 \pm 1.21$ vs. $0.36 \pm 0.68$, $P<0.0001)$; outpatient medical service claims (110.18 \pm 101.03 vs. $66.98 \pm 72.43, \quad P<0.0001)$; and outpatient prescription claims $(52.13 \pm 35.30$ vs. $44.29 \pm 32.41, P<0.0001)$ were significantly greater for the dyspeptic cohort, relative to the nondyspeptic cohort, as were the associated costs (inpatient services: $\$ 23,610 \pm \$ 54,748$ vs. $\$ 5,509 \pm \$ 19,142, P<0.0001$; outpatient medical service claims: $\$ 18,182 \pm \$ 28,790$ vs. $\$ 9,765 \pm \$ 22,009$, $P<0.0001$; outpatient prescriptions: $\$ 4,661 \pm \$ 5,628$ vs. $\$ 3,897$ $\pm 4,586, P<0.0001$; Figure 2).

\section{Sensitivity Analysis}

Using the sensitivity multivariable regression models, in which the impact of dyspepsia on health care utilization for all causes along with associated costs among the unmatched cohorts were determined, we found the results to be consistent with those of the matched cohorts (Table 4). The mean incremental health care resource utilization measurements as the differences in inpatient claims (count: 0.90; payment: $\$ 11,274$ ); total hospital LOS (7.32 days); outpatient medical service claims (count: 45.99; payment: $\$ 9,273$ ); and outpatient prescriptions (count: 8.07; payment: \$805), as well as their associated costs for the dyspeptic cohort versus the nondyspeptic cohort, were all statistically significant $(P<0.0001)$.

\section{Warfarin Use}

Among the matched study population, $60.70 \%$ of NVAF patients with no dyspepsia, $46.27 \%$ of NVAF patients with nonchronic dyspepsia, and $42.39 \%$ of NVAF patients with chronic dyspepsia $(P<0.0001)$ were treated with warfarin during the baseline period. These results were similar during the follow-up period (no dyspepsia: $57.16 \%$, nonchronic dyspepsia: $50.44 \%$, chronic dyspepsia: $46.63 \%$ ), and this trend of decreased warfarin use among dyspeptic NVAF patients was observed at any stroke risk: $\mathrm{CHADS}_{2}=0-1$ (no dyspepsia: 55.63\%, nonchronic dyspepsia: 50.09\%, chronic dyspepsia: 45.45\%); $\mathrm{CHADS}_{2}=2$ (no dyspepsia: $57.81 \%$, nonchronic dyspepsia: $51.19 \%$, chronic dyspepsia: $48.12 \%$ ); and $\mathrm{CHADS}_{2} \geq 3$ (no dyspepsia: $58.91 \%$, nonchronic dyspepsia: $50.10 \%$, chronic dyspepsia: $46.50 \%)$.

\section{Discussion}

This study is the first to evaluate the incremental health care burden associated with dyspepsia among NVAF patients using health care claims records. The results of this study suggest dyspepsia significantly impacts health care resource use and costs, which for all health care claims were 2.4-fold higher among NVAF patients with dyspepsia relative to NVAF patients without dyspepsia (matched study population). Moreover, dyspepsia was associated with worse patient outcomes as indicated by a greater number of hospitalizations, irrespective of cause. These results were consistent when evaluated for unmatched cohorts using multivariable regression analysis. Among matched dyspeptic NVAF patients, dyspepsia-related hospitalizations accounted for approximately half of all hospitalizations per patient year with a mean cost of $\$ 13,450$. In a recent cost-effective analysis of novel oral anticoagulants versus warfarin, Harrington et al. (2013) estimated the cost of dyspepsia among NVAF patients treated with dabigatran at $\$ 6,648 .{ }^{13}$ This lower cost estimate compared with that observed in our 


\section{TABLE 3 Medical Service Claims and Associated Payments for NVAF Patients}

\begin{tabular}{|c|c|c|c|c|c|c|}
\hline \multirow[b]{2}{*}{ Outcome } & \multicolumn{4}{|c|}{$\begin{array}{l}\text { Matched Cohorts } \\
\qquad(\mathrm{N}=28,172)\end{array}$} & \multirow[b]{2}{*}{ Difference } & \multirow[b]{2}{*}{$P$ Value } \\
\hline & \multicolumn{2}{|c|}{$\begin{array}{c}\text { Dyspeptic } \\
(\mathrm{n}=14,086)\end{array}$} & \multicolumn{2}{|c|}{$\begin{array}{l}\text { Nondyspeptic } \\
(\mathrm{n}=14,086)\end{array}$} & & \\
\hline \multicolumn{7}{|c|}{ Hospitalizations per patient year (mean \pm SD) } \\
\hline Dyspepsia-related & \multicolumn{2}{|c|}{$0.65 \pm 0.66$} & \multicolumn{2}{|c|}{ NA } & 0.65 & NA \\
\hline GI-related & \multicolumn{2}{|c|}{$0.83 \pm 0.86$} & \multicolumn{2}{|c|}{$0.06 \pm 0.25$} & 0.77 & $<0.0001$ \\
\hline GI bleed-related & \multicolumn{2}{|c|}{$0.10 \pm 0.34$} & \multicolumn{2}{|c|}{$0.02 \pm 0.14$} & 0.08 & $<0.0001$ \\
\hline \multicolumn{7}{|c|}{ Frequency of patients with hospitalization (n, \%) } \\
\hline Dyspepsia-related & 8,192 & 58.16 & NA & NA & 58.16 & NA \\
\hline GI-related & 9,086 & 64.50 & 716 & 5.08 & 59.42 & $<0.0001$ \\
\hline GI bleed-related & 1,237 & 8.78 & 226 & 1.60 & 7.18 & $<0.0001$ \\
\hline \multicolumn{7}{|c|}{ Hospitalization length of stay (days) per patient year (mean \pm SD) } \\
\hline Dyspepsia-related & \multicolumn{2}{|c|}{$4.91 \pm 8.59$} & \multicolumn{2}{|c|}{ NA } & 4.91 & NA \\
\hline GI-related & \multicolumn{2}{|c|}{$6.21 \pm 11.07$} & \multicolumn{2}{|c|}{$0.34 \pm 2.47$} & 5.87 & $<0.0001$ \\
\hline GI bleed-related & \multicolumn{2}{|c|}{$1.10 \pm 5.27$} & \multicolumn{2}{|c|}{$0.14 \pm 1.87$} & 0.96 & $<0.0001$ \\
\hline \multicolumn{7}{|c|}{ Hospitalization payment per patient year $(\$$, mean \pm SD $)$} \\
\hline Dyspepsia-related & \multicolumn{2}{|c|}{$13,450 \pm 36,808$} & \multicolumn{2}{|c|}{ NA } & 13,450 & NA \\
\hline GI-related & \multicolumn{2}{|c|}{$17,258 \pm 45,742$} & \multicolumn{2}{|c|}{$997 \pm 9,262$} & 16,261 & $<0.0001$ \\
\hline GI bleed-related & \multicolumn{2}{|c|}{$2,749 \pm 16,948$} & \multicolumn{2}{|c|}{$416 \pm 5,752$} & 2,333 & $<0.0001$ \\
\hline \multicolumn{7}{|c|}{ Outpatient medical service claims per patient year $($ mean \pm SD) } \\
\hline Dyspepsia-related & \multicolumn{2}{|c|}{$6.29 \pm 10.53$} & \multicolumn{2}{|c|}{ NA } & 6.29 & NA \\
\hline GI-related & \multicolumn{2}{|c|}{$14.93 \pm 21.98$} & \multicolumn{2}{|c|}{$1.41 \pm 6.45$} & 13.52 & $<0.0001$ \\
\hline GI bleed-related & & & & & 0.50 & $<0.0001$ \\
\hline Outpatient medica & patient & lean \pm SD & & & & \\
\hline Dyspepsia-related & & & & & 965 & NA \\
\hline GI-related & & & & & 2,602 & $<0.0001$ \\
\hline GI bleed-related & & & & & 107 & $<0.0001$ \\
\hline
\end{tabular}

study was based on the 1-time event cost of a hospital stay with a primary diagnosis of dyspepsia from the Healthcare Cost and Utilization Nationwide Inpatient Sample. ${ }^{13}$ In our study, the incremental dyspepsia-related hospitalization cost was derived from medical claims records, specifically among an NVAF population with a primary or secondary diagnosis of dyspepsia identified from the MarketScan Commercial and Medicare Research databases.

Using ICD-9-CM codes on claims records, we found that a diagnosis of dyspepsia was present in $10.4 \%$ of NVAF patients, which is substantially lower than the 34\% reported in the recent Internet-based survey conducted by LaMori et al. (2012). ${ }^{6}$ The disparity in findings may be explained by a difference in data collection methodology, as the current study evaluated NVAF patients with dyspepsia who sought medical care and were therefore captured in the medical claims database, while the survey determined the prevalence of dyspepsia based on AF patients self-reporting symptoms/associated conditions of dyspepsia. ${ }^{6}$ Additionally, while LaMori et al. reported greater use of outpatient health care resources among dyspeptic AF patients, consistent with the results of our study, the number of hospitalizations in their case was similar among dyspeptic and nondyspeptic AF patients. These latter findings contrast with ours, as we observed that dyspeptic NVAF patients had a 3.4-fold increased number of hospitalizations for any cause, relative to NVAF patients who did not have dyspepsia. The population of the LaMori et al. study was younger, having mean ages of 63 years (dyspeptic) and 66 years (nondyspeptic), and this lesser age may in part account for the lower number of hospitalizations observed in this study compared with our study, in which the mean age of the matched study population was 74 , with greater than half of the study population above the age of $76 .{ }^{6}$ Although our results on inpatient resource use contrasted with that of LaMori et al., they are similar to those of the study by Kinoshita et al. (2013), which reported that AF patients with dyspepsia had more than twice the number of hospitalizations in the past 6 months compared with AF patients without dyspepsia.

Consistent with what was previously reported, comorbidity and stroke risk among NVAF patients were greater for those with dyspepsia, and a greater proportion of patients with dyspepsia were female. ${ }^{6}$ Also consistent with that reported by LaMori et al., we found that NVAF patients who had dyspepsia were less likely to be taking warfarin, despite having 


\section{FIGURE 2 Health Care Resource Utilization for All Causes and Associated Payments}

\section{A}

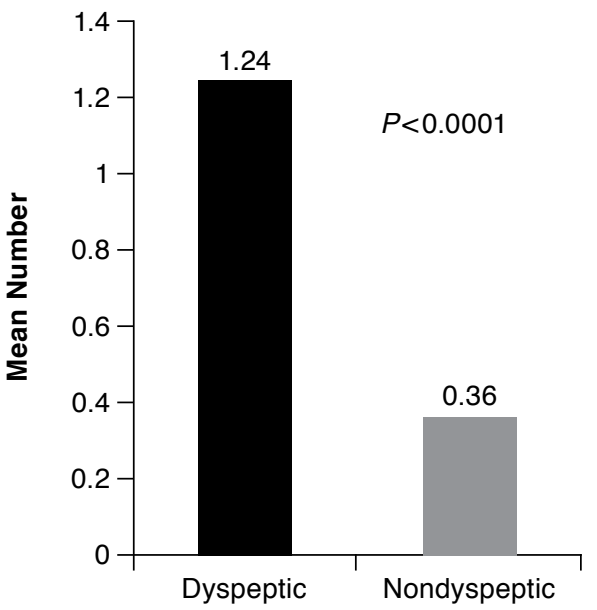

Outpatient Medical Service Claims

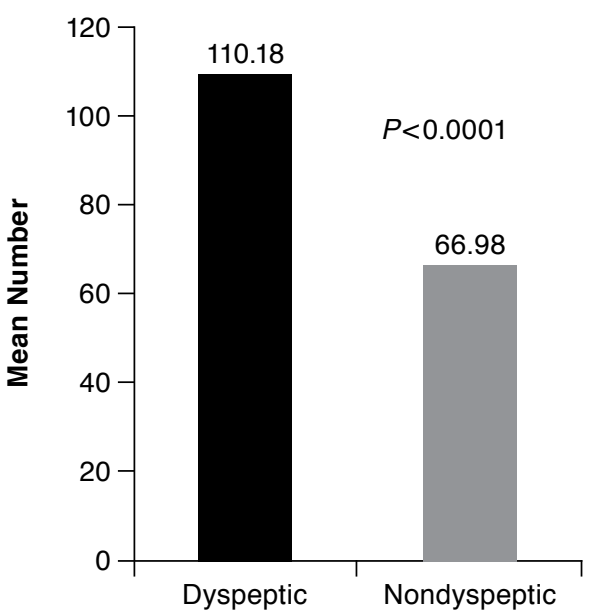

Outpatient Prescription Claims

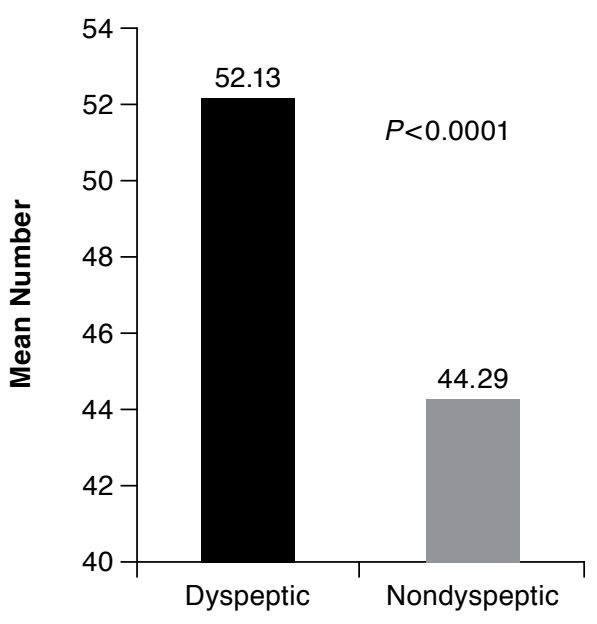

B

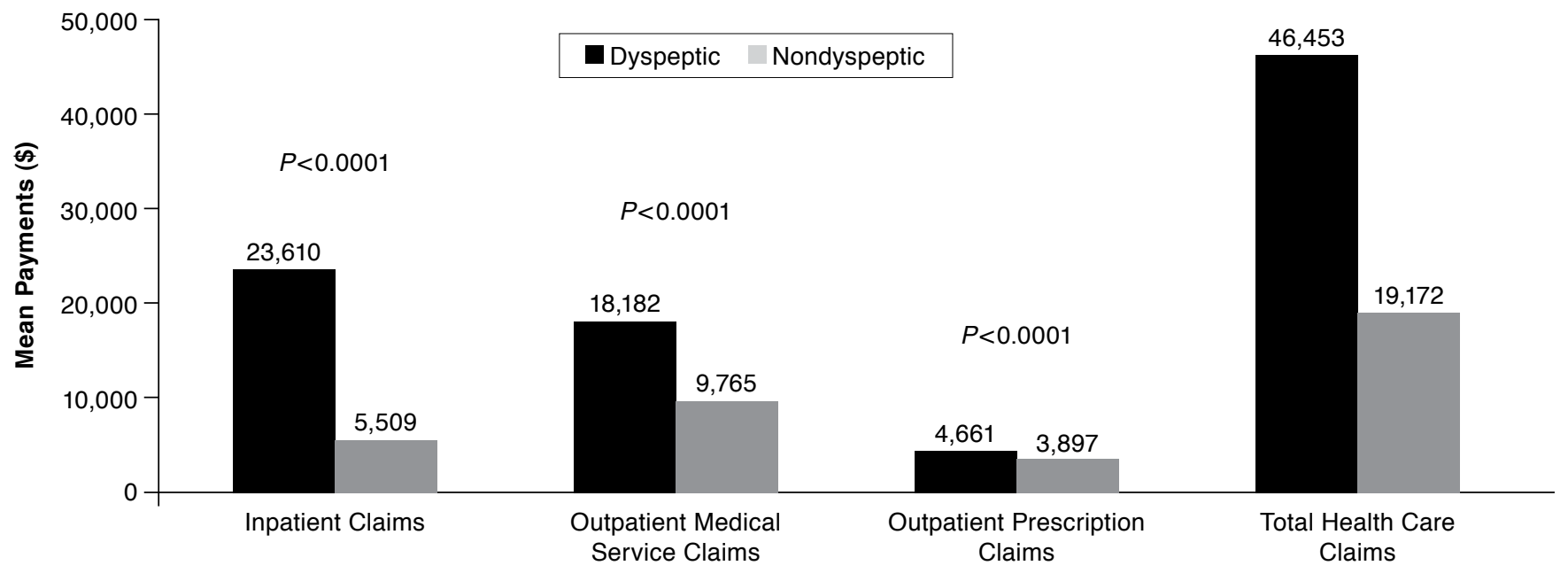

greater stroke risk than NVAF patients without dyspepsia. ${ }^{6}$ In addition, we found that NVAF patients with dyspepsia were 5 times more likely to be hospitalized for a GI bleed than NVAF patients who did not have dyspepsia. Concerns over the risk of bleeding is one of the challenges of initiating warfarin treatment. The concern that dyspepsia may be a manifestation or precursor of GI bleeding may partly explain why dyspepsia appeared to be a barrier to warfarin therapy in this study. ${ }^{14}$

Undertreatment of NVAF patients with warfarin is associated with greater risk for stroke with a large retrospective analysis of NVAF patients who were treated with warfarin versus those who were candidates for warfarin therapy, reporting that warfarin therapy was associated with reduced risks of ischemic stroke (reduced 22\%) and thromboembolism (reduced
34\%). ${ }^{15}$ Moreover, a recent study, also conducted on a large managed care population, found that $51.4 \%$ of NVAF patients who initiated warfarin therapy discontinued the therapy, and during discontinuation periods, stroke risk increased 1.60-fold compared with therapy periods. ${ }^{16}$ Based on clinical trial data, the stroke risk of NVAF patients treated with rivaroxaban who discontinue treatment is also elevated after temporarily or permanently discontinuing anticoagulation therapy. ${ }^{17}$ As the underuse and discontinuation of warfarin therapy are high, especially among elderly NVAF patients, it will be important to re-evaluate treatment patterns of anticoagulation therapy in the near future, since the choices of oral anticoagulants for treatment of NVAF patients have increased with the introduction of dabigatran, rivaroxaban, and apixaban to the market. ${ }^{8,9,16}$ 


\section{TABLE 4 Multivariable Regression Analysis of Mean Differences in All Health Care Resource Utilization}

\begin{tabular}{|c|c|c|}
\hline & $\begin{array}{c}\text { Mean } \\
\text { Difference } \\
\text { Dyspepsia: } \\
\text { Yes/No }\end{array}$ & $\begin{array}{c}P \\
\text { Value }\end{array}$ \\
\hline \multicolumn{3}{|l|}{ All health care resource use } \\
\hline Inpatient claims count & 0.90 & $<0.0001$ \\
\hline Hospital length of stay (days) & 7.32 & $<0.0001$ \\
\hline Outpatient medical service claims count & 45.99 & $<0.0001$ \\
\hline Outpatient Rx claims count & 8.07 & $<0.0001$ \\
\hline \multicolumn{3}{|l|}{ All health care resource payment (\$) } \\
\hline Total resource payment (inpatient + outpatient $+\mathrm{Rx}$ ) & 29,830 & $<0.0001$ \\
\hline Total inpatient payment & 11,274 & $<0.0001$ \\
\hline Outpatient medical service payment & 9,273 & $<0.0001$ \\
\hline Outpatient Rx payment & 805 & $<0.0001$ \\
\hline
\end{tabular}

\section{Limitations}

While our study yields informative data on the health care burden of dyspepsia among a large population of real-world NVAF patients, there are limitations that need to be taken into account when evaluating results from retrospective database analyses, including, most importantly, the fact that our results imply an association of dyspepsia and increased health care utilization and not causation. Also, dyspepsia is a GI disorder in which the symptoms overlap with those of other GI disorders. Dyspepsia also frequently coexists with other GI disorders, such as GERD and irritable bowel syndrome. ${ }^{10}$ These attributes of dyspepsia may have caused it to be underreported in the MarketScan Commercial and Medicare Research databases. Additionally, claims in these databases are subject to coding errors, coding for the purpose of rule-out rather than actual disease, and undercoding, either by the health care provider or because of limitations imposed by the database. Other patient variables, such as duration of NVAF, body mass index, socioeconomic factors, and race were not taken into account in this analysis and may have influenced the results. Furthermore, the identification of dyspepsia by ICD-9-CM codes is likely less sensitive for the detection of dyspeptic patients than self-reporting, as previously mentioned. Therefore, the dyspeptic patient cohorts may not fully represent the entire NVAF patient population with dyspepsia (e.g., NVAF patients with mild symptoms of dyspepsia, undiagnosed dyspepsia, or sporadic symptoms of dyspepsia).

Although 97\% of patients with dyspepsia were exactly matched to nondyspeptic patients, after the matching process the nondyspeptic cohort represented only $11 \%$ of the overall nondyspeptic cohort, which may influence the generalizability of this study population to other nondyspeptic NVAF patients. However, in the sensitivity analysis in which key measurements were also evaluated among unmatched cohorts using multivariable regression, the results were found to be consistent with those of the matched cohorts. Lastly, we used a t-test to compare cost data, which assumes a normal distribution and in some cases cost data are not normally distributed, but according to the Central Limit Theorem, the sample size of our matched study population was more than adequate and comparison of cost data by t-test appropriate. Furthermore, multiple additional studies have been conducted using similar methods to compare cost data. ${ }^{18-20}$ Nonetheless, we also carried out the comparison of key cost measurements of matched dyspeptic and nondyspeptic cohorts using a nonparametric Kruskal-Wallis test instead of the t-test. All the $P$ values were confirmed to be $<0.0001$, consistent with the t-test results.

\section{Conclusions}

Dyspepsia significantly impacts health care resource use and costs among NVAF patients. Moreover, it is associated with worse patient outcomes as indicated by a greater number of hospitalizations and longer hospital stays, irrespective of cause. Warfarin use was significantly lower among NVAF patients with dyspepsia, independent of stroke risk, suggesting dyspepsia may be a potential barrier to its use. Improved management of dyspepsia and further knowledge of its impact on patients with NVAF may help to facilitate appropriate anticoagulation strategies in these patients and perhaps achieve better outcomes.

\section{Authors}

MICHAEL H. KIM, MD, is Director, Arrhythmia Service, and Director, Electrophysiology Fellowship Program, Warren Alpert Medical School of Brown University, Cardiovascular Institute, Rhode Island and Miriam Hospitals, Providence, Rhode Island. KELLY F. BELL, PharmD, MSPhr, is Associate Director, Metabolics Health Services; DINARA MAKENBAEVA, MD, is Associate Director; and JOHN GRAHAM, PharmD, is Executive Director, Bristol-Myers Squibb, Plainsboro, New Jersey. DANIEL WIEDERKEHR, BS, is Director of Real World Data \& Analytics, Pfizer, New York, New York, and JAY LIN, PhD, MBA, is Managing Director, Novosys Health, Flemington, New Jersey.

AUTHOR CORRESPONDENCE: Michael H. Kim, MD, Director, Arrhythmia Service, and Director, Electrophysiology Fellowship Program, Warren Alpert Medical School of Brown University, Cardiovascular Institute, Rhode Island and Miriam Hospitals, 593 Eddy St., APC 739, Providence, RI 02903. Tel.: 401.444.5328; Fax: 401.444.4652; E-mail: mkim4@lifespan.org. 


\section{DISCLOSURES}

This research was supported by Bristol-Myers Squibb and Pfizer. Kim is a consultant to Sanofi, Boehringer-Ingelheim, and Novosys Health, and is on the speaker's bureau for Sanofi and Boehringer-Ingelheim. Lin is an employee of Novosys Health, which has received research funds from Bristol-Myers Squibb and Pfizer in connection with conducting this study and development of this manuscript. Bell, Makenbaeva, and Graham are employees of BristolMyers Squibb and own stock in the company. Wiederkehr is an employee of Pfizer and owns stock in the company.

Study concept and design were primarily contributed by Makenbaeva, Lin, and Kim, with data collection by Bell, Wiederkehr, Lin, and Graham. Interpretation of data was done primarily by Lin and Kim. The manuscript was written mostly by Kim, aided by Graham and the other authors, and all authors participated in revision.

\section{ACKNOWLEDGMENTS}

We would like to acknowledge Melissa Lingohr-Smith from Novosys Health for editorial support and review of this manuscript, which was financially supported by Bristol-Myers Squibb and Pfizer.

\section{REFERENCES}

1. Go AS, Hylek EM, Phillips KA, et al. Prevalence of diagnosed atrial fibrillation in adults: national implications for rhythm management and stroke prevention: the AnTicoagulation and Risk Factors in Atrial Fibrillation (ATRIA) Study. JAMA. 2001;285(18):2370-75. Available at: http://jama.jamanetwork.com/article.aspx?articleid=193807. Accessed December 4, 2013.

2. Naccarelli GV, Varker H, Lin J, Schulman KL. Increasing prevalence of atrial fibrillation and flutter in the United States. Am J Cardiol. 2009;104(11):1534-39.

3. Wolf PA, Abbott RD, Kannel WB. Atrial fibrillation as an independent risk factor for stroke: the Framingham Study. Stroke. 1991;22(8):983-88. Available at: http://stroke.ahajournals.org/content/22/8/983.long. Accessed December 4, 2013

4. Loyd RA, McClellan DA. Update on the evaluation and management of functional dyspepsia. Am Fam Physician. 2011;83(5):547-52. Available at: http://www.aafp.org/afp/2011/0301/p547.html. Accessed December 5, 2013.

5. Sobieraj DM, Coleman SM, Coleman CI. US prevalence of upper gastrointestinal symptoms: a systematic literature review. Am J Manag Care. 2011;17(11):e449-58. Available at: http://www.ajmc.com/publications/ issue/2011/2011-11-vol17-n11/US-Prevalence-of-Upper-GastrointestinalSymptoms-A-Systematic-Literature-Review. Accessed December 5, 2013.

6. LaMori JC, Mody SH, Gross HJ, et al. Dyspepsia and disease burden among patients with atrial fibrillation. Crit Pathw Cardiol. 2012;11(1):14-19.

7. Kinoshita Y, Dibonaventura M, Rossi B, Iwamoto K, Wang EC, Briere JB. Burden of comorbidities among Japanese patients with atrial fibrillation: a case study of dyspepsia. Clin Exp Gastroenterol. 2013;6:51-59.

8. Gage BF, van Walraven C, Pearce $L$, et al. Selecting patients with atrial fibrillation for anticoagulation: stroke risk stratification in patients taking aspirin. Circulation. 2004;110(16):2287-92. Available at: http://circ.ahajournals.org/content/110/16/2287.long. Accessed December 5, 2013.
9. LaMori JC, Mody SH, Gross HJ, et al. Burden of comorbidities among patients with atrial fibrillation. Ther Adv Cardiovasc Dis. 2013;7(2):53-62.

10. Sobieraj DM, White CM, Alikhanov S, et al. The impact of antiplatelet and anticoagulant therapies on gastrointestinal symptoms in patients with atrial fibrillation: a systematic review. Ann Pharmacother. 2012;46(9):1220-31.

11. Connolly SJ, Ezekowitz MD, Yusuf S, et al. Dabigatran versus warfarin in patients with atrial fibrillation. New Engl J Med. 2009;361(12):113951. Available at: http://www.nejm.org/doi/full/10.1056/NEJMoa0905561. Accessed December 5, 2013.

12. Bunch TJ, Packer DL, Jahangir A, et al. Long-term risk of atrial fibrillation with symptomatic gastroesophageal reflux disease and esophagitis. Am J Cardiol. 2008;102(9):1207-11. Available at: http://www.ncbi.nlm.nih.gov/ pmc/articles/PMC2895499/. Accessed December 5, 2013.

13. Harrington AR, Armstrong EP, Nolan PE Jr, Malone DC. Cost-effectiveness of apixaban, dabigatran, rivaroxaban, and warfarin for stroke prevention in atrial fibrillation. Stroke. 2013;44(6):1676-81. Available at: http://stroke.ahajournals.org/content/44/6/1676.long. Accessed December 5, 2013

14. Baczek VL, Chen WT, Kluger J, Coleman CI. Predictors of warfarin use in atrial fibrillation in the United States: a systematic review and meta-analysis. BMC Fam Pract. 2012;13:5. Available at: http://www.ncbi.nlm.nih.gov/ pmc/articles/PMC3395868/. Accessed December 5, 2013

15. Darkow T, Vanderplas AM, Lew KH, Kim J, Hauch O. Treatment patterns and real-world effectiveness of warfarin in nonvalvular atrial fibrillation within a managed care system. Curr Med Res Opin. 2005;21(10):1583-94.

16. Deitelzweig SB, Buysman E, Pinsky B, et al. Warfarin use and stroke risk among patients with nonvalvular atrial fibrillation in a large managed care population. Clin Ther. 2013;35(8):1201-10.

17. Patel MR, Hellkamp AS, Lokhnygina Y, et al. Outcomes of discontinuing rivaroxaban compared with warfarin in patients with nonvalvular atrial fibrillation: analysis from the ROCKET AF trial (Rivaroxaban Once-Daily, Oral, Direct Factor Xa Inhibition Compared With Vitamin K Antagonism for Prevention of Stroke and Embolism Trial in Atrial Fibrillation). J Am Coll Cardiol. 2013;61(6):651-58.

18. Mercaldi CJ, Siu K, Sander SD, et al. Long-term costs of ischemic stroke and major bleeding events among Medicare patients with nonvalvular atrial fibrillation. Cardiol Res Pract. 2012;2012:645469. Available at: http://www. ncbi.nlm.nih.gov/pmc/articles/PMC3467774/. Accessed December 5, 2013.

19. Kim MH, Johnston SS, Chu BC, Dalal MR, Schulman KL. Estimation of total incremental health care costs in patients with atrial fibrillation in the United States. Circ Cardiovasc Qual Outcomes. 2011;4(3):313-20. Available at: http://circoutcomes.ahajournals.org/content/4/3/313.long. Accessed December 5, 2013.

20. McAdam-Marx C, McGarry LJ, Hane CA, Biskupiak J, Deniz B, Brixer DI. All-cause and incremental per patient per year cost associated with chronic hepatitis $C$ virus and associated liver complications in the United States: a managed care perspective. J Manag Care Pharm. 2011;17(7):53146. Available at: http://www.amcp.org/WorkArea/DownloadAsset. aspx?id=10710. 